\title{
How to Build a Linkage between High-Quality Assurance Production System and Production Support Automated System
}

\author{
Hirohisa Sakai
}

Toyota Motor Corporation

\begin{abstract}
To maintain the planned production volume for potential disaster, the Japanese manufacturing industry needs to develop and rebuilt the global product that is to strengthen QCD (Quality, Cost, and Delivery). The keys to fulfilling this need are automated facility, human skills to operate the facility (production operator), and a production system incorporated with production data systems that activate the facility and human system subject to each overseas plant conditions. Therefore, the author has created a new system that ensures the necessity of building a new production system for global production, eliminates ambiguity among the processes of production planning, production preparation, production and process control, and formalizes and builds the linkage among the processes. This paper is to reveal the effectiveness of the above-specified objectives of the newly created systems. Especially the highly accurate robot production system has been tested and confirmed at Toyota Motor Corporation.
\end{abstract}

Keywords: Global production, Highly reliable production systems, Automotive manufacturing.

\section{INTRODUCTION}

The Japanese manufacturing industry needs to develop global product that is to strengthen QCD (Quality, Cost, and Delivery) to provide high reliability and trust for global customers. The keys to fulfilling this need are automated equipment, human skills to operate the equipment (production operator), and a production system incorporated with production data that activates the facility and human system. In this environment, the author has created a new system that ensures the necessity of building a new production system for global production, eliminates ambiguity among the processes of production planning, production preparation, production and process control, and formalizes and builds the linkage among these processes.

The objectives of the new system are to (i) solve technical problems in advance in a production planning process by simulating technical problems with computer graphics created in CAE (Computer-Aided Engineering) (ii) improve production operators' skills to operate automated equipment and manufacturing technology, and (iii) create the production data that network and visualize the above objectives by the aid of IT.

The effectiveness of the above-specified objectives of the newly created system has been tested and confirmed by a leading manufacturer, Toyota Motor Corporation.

\footnotetext{
*Address correspondence to this author at the Toyota Motor Corporation; Tel: +81-50-3167-6669;
}

E-mail: h_sakai@mail.toyota.co.jp; sakai1188295@gmail.com

\section{THE EXPANDING NEED FOR HIGHLY RELIABLE PRODUCTION SYSTEM FOR GLOBAL PRODUCTION}

The Current Condition and Problems of the
Conventional Production System

Today's manufacturers in Japan are globally expanding their operations at a full speed to be price competitive and need to establish a new production system to suit their global strategies. Conventionally, well-experienced and highly-skilled trainers go to local production sites and provide local production operators with one-on-one hands-on training.

The quality of training for production operators greatly relies on the personal capabilities of the highly skilled trainers. Different trainers would give different pieces of training, which may confuse trainees and result in unevenness in production operators' skill acquisition processes. Production operators in Japan also have experienced the same problems while passing down the Japanese manufacturing technology.

To solve these problems, manufacturing plants whose main production sites are domestic and overseas countries have expected digital engineering to change production processes and adopted IT since the late 1990s. Various IT production systems have been introduced at those plants to operate the equipment designed to expand their manufacturing technology overseas (Chand and Shirvani, 2000; Sakai and Amasaka, 2007a). However, for some of the plants, despite the large investment in IT, the lack of training and policies for the training have prevented their production operators from improving their 
operating skills for advanced production equipment and acquiring high-level skills (Dhudshia, 1996; Morikiyo, 1996).

This situation causes that the industry expected a simple introduction of IT tools and IT production systems to bring advanced production systems, and the initial introduction became their ultimate purpose while how to develop the introduced IT was not wellthought yet. Another reason is that there is much vagueness in judging and sharing workers' skills and work habits which affect greatly manufacturing technology. Skills both as an individual and as a team, know-how, and managing rules are vague, which prevents the introduced IT from working effectively. This is a common problem among many other manufacturing industries.

To improve a product line and win in the global quality competition, the most urgent and important is to clearly define work methods (production systems) that affect the manufacturing technology both in Japan and in developing countries, to start operation smoothly, and to establish the manufacturing technology environments that guarantee the high quality (Amasaka, 2007; Liker, 2004; Liker and Hoseus, 2008; Morgan and Liker, 2006).

\section{The Necessity of Building the Linkage among the Production Processes}

Under the current environments, no researcher started a study on how to create steps from lectures and training to actual, on-site jobs for production operators. The quality and contents of those training and following phases are not standardized and depend on trainers' capabilities.

As global production is expanding rapidly, this has become a serious problem; the quality and contents of training vary among trainers for various processes, which may cause workers to redo or even stop processes especially in the case of replacing workers. Production operators need to create a combination of processes in process planning and be well-prepared so that they can easily do the processes. Simulating with digital engineering will prevent potential, technical problems in logistics, deciding the number of buffers, and placing operators.

For this reason, to create a Highly Reliable Production system for global production, which improves the reliability of the manufacturing technology and enables continued growth of the industry, it is indispensable to build processes in production planning, production preparation, production, and process control, and a linkage to systematically operate those processes (Amasaka, 2004; Amasaka and Sakai, 2011)

\section{Need of the Linkage for Expanding Global Production}

There will be a need for network systems for production operators in the entire, global industry to build the linkage mentioned above. In those systems, it is necessary to share and integrate information globally while respecting local characteristics. There are no studies on unified systems for all the linguistically diverse production operators to understand at the same level. For these reasons, it is urgently needed to build the linkage for expanding global production.

\section{IDEAS FOR HIGHLY RELIABLE PRODUCTION SYSTEMS FOR GLOBAL PRODUCTION}

\section{Ideas for a Highly Reliable Production System for Global Production}

The author has proposed that there are three important points to assure high quality and high efficiency, and shorten lead time:

(1) Production equipment using industrial robots,

(2) Skilled workers who operate the equipment (production operators), and

(3) Production system including production data systems that activate the equipment and workers

Figure 1 shows a Highly Reliable Production System for global production. The main factors of a Highly Reliable Production System for global production are to build a linkage among individual processes in production planning, production preparation, actual production, and process control, to make those processes as perfect as possible, and to raise reliability in the manufacturing technology for global production. (Sakai and Amasaka, 2007b; Sakai and Amasaka, 2007c).

The missions of Highly Reliable Production System for global production are to (i) solve technical problems in advance in a production planning process by simulating technical problems with computer graphics created in CAE (Computer-Aided Engineering), (ii) improve production operators' skills to operate automated equipment and the manufacturing 


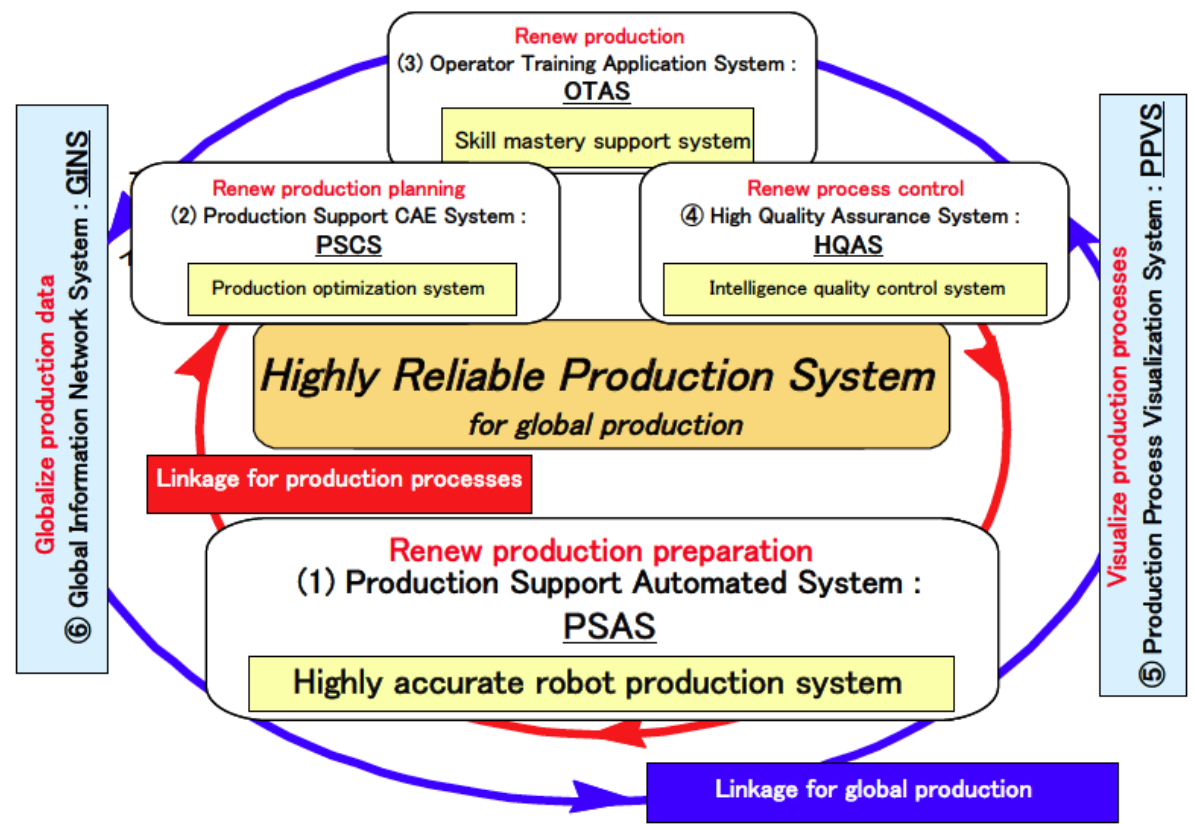

Figure 1: Highly Reliable Production System for global production.

technology, and (iii) create production data that network and visualize the above objectives by the aid of IT.

To fulfill those missions, one requirement is that production operators must create a combination of processes in process planning and be well-prepared so that they can easily do the processes. Digital engineering will lead to building a linkage among production processes to prevent technical problems including:

(1) Integrity between advanced equipment and its operators' skills

(2) Integrity between production operators' skills and their movements

(3) Integrity among facility, its production operators' skills, and parts

(4) Another requirement is network systems that enable production operators to build the linkage. It is required urgently to build the linkage that disperses and integrates information globally while respecting local independence.

Four essential techniques to build the linkage among production processes in Highly Reliable Production System for global production.

The idea in Figure 1 to build the linkage among production processes in a Highly Reliable Production
System for global production consists of the following four essential techniques.

(1) PSAS: Production Support Automated System

(2) PSCS: Production Support CAE System

(3) OTAS: Operator Training Application System

(4) HQAS: High-Quality Assurance Production System

To use PSAS mainly, it is important to plan precisely from production planning stages and prevent problems by simulating. (i) Reforming production planning: CAE data simulation will optimize production requirements regarding production lines (logistics and transportation), robots (placing arrangement) and production operators (allocation and workability) for the entire plant and (ii) reforming production preparation: Highly accurate robot production system will replace heavy load processes that are currently done manually by workers.

Two Essential Techniques to Build the Linkage to Globally Develop Highly Reliable Production System

The following two systems will support building the linkage to globally develop Highly Reliable Production Systems among production operators. 
To use PPVS (Production Process Visualization System), and GINS (Global Information Network System), in Figure 1, the additional, following two systems are required.

(1) Systems to visualize production processes in planning, preparation, and process control and gain better results of $Q C D$ activities

(2) Servers and client systems to use production data globally

All of these above will implement a Highly Reliable Production System for global production to immediately establish the manufacturing technology that assures high quality (Sakai and Amasaka, 2006).

\section{DEMONSTRATING THE EFFECTIVENESS AND FEASIBILITY OF A HIGHLY RELIABLE PRODUCTION SYSTEM FOR GLOBAL PRODUCTION}

To describe an example to apply the Highly Reliable Production System for global production, this chapter explains the highly accurate robot production systems at Toyota.

Example: research to build the linkage between PSAS and HQAS

As a research example of building PSAS in production preparation, this section describes a highly accurate robot production system that gives highquality assurance for global production.

\section{OUTLINE OF CSE (CURVED SEAL EXTRUSION) MOLE}

Recently, those parts that protrude out of the stamped body surface are decreasing due to the requirement of flush-surfacing of vehicles. Currently,
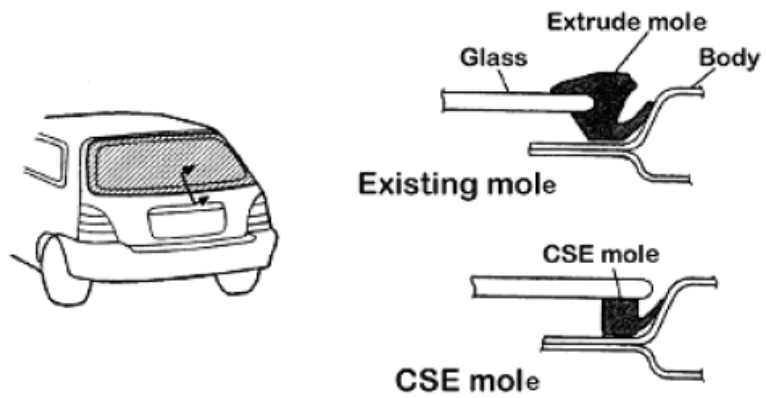

Figure 2: CSE mole. the adopted mole that attaches around the automobile window is the type that sticks onto the back of the glass so that it does not protrude to the top surface, as shown in Figure 2.

In manufacturing this type of mole, one method is to stick the extruded mole onto the glass, and another is to inject the mole onto the glass inside a die. The extruding method has a high level of general-purpose application because the cross-sectional shape of the mole can be changed by merely changing the die head of the extruding machine. However, this method has two disadvantages. One is the difficulty of ensuring precision when the mole is stuck onto the glass. And the other is that mole is easily distorted around the corners of the glass.

As for the integrated injection mole method, this is difficult to apply to large glass such as the rear automobile window, which has large curvature, because the glass is easily cracked in a die during the injection. The CSE mole is produced by putting adhesive to the back of the automobile window glass and then extruding the mole onto it. The hot plastics cause the adhesive to react, thus sticks to the glass. In this way, as shown in Figure 3, when the glass moves in the lengthwise direction of the mole, the extruded mole sticks to the glass. The manufacturing consists of a glass locating process, extruding process, and swingout process. The equipment consists of a robot to hold the glass and the extruding machine to form the mole (Figure 4).

The following two technological requirements must be met for mass-production of CSE mole; extruding the mole with high productivity and extruding the mole with necessary appearance quality.

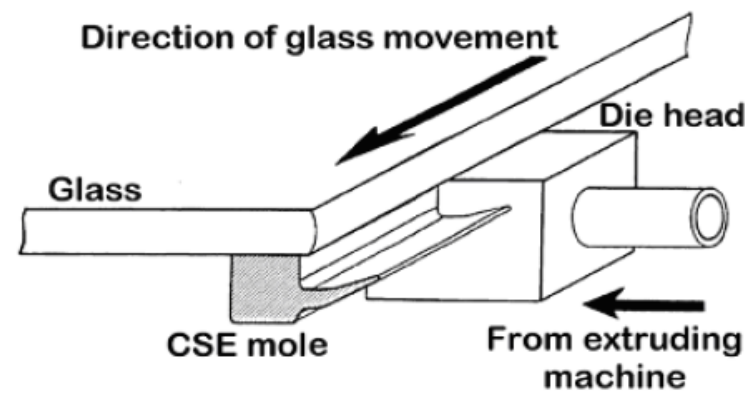

Figure 3: Principle of CSE mole adhesion. 


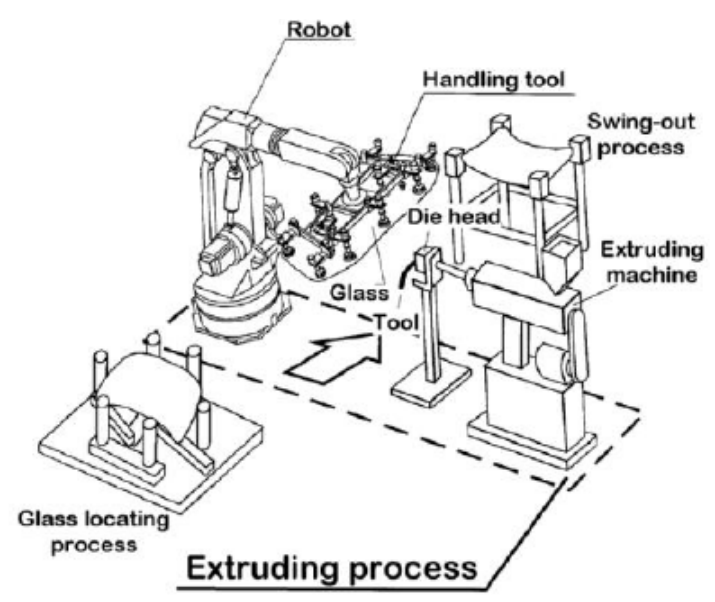

Figure 4: Process drawing.

\section{IMPROVING PRODUCTIVITY}

\subsection{Step 1: The Die Head Position and the Robot Control Functions}

The author has set the target extrusion time to be $40 \mathrm{sec}$ per sheet (the moving speed of the glass along the die head is $80 \mathrm{~mm} / \mathrm{sec}$ ). The robot, holding the glass, places the side of the glass in contact with the die head and moves the glass along its tangent direction at a constant speed. When the curvature radius of the glass side is greater than the distance from the glass side to the centre of the tool mounting area, a moving speed required for moving the tool mounting area is lower than the speed of the die head in the tangent direction of the glass. However, as the curvature of the glass side becomes smaller, the moving speed of the tool mounting area accelerates.

As shown in Figure 5, the tool mounting area $(\mathrm{mm} / \mathrm{sec}), \mathrm{vb}$ is required as the following:

$v b=\{(R-r) / r\} \times v a$

where $r$ is the curvature radius of the glass side $(\mathrm{mm})$, $R$ is the distance from the glass side to the center of the tool mounting area $(\mathrm{mm})$, and VA is the moving speed of the glass along with the die head $(\mathrm{mm} / \mathrm{sec})$.

The measurements show that a speed reduction occurs at the corner where the curvature is small when the moving speed, in the glass tangent direction relative to the die head, exceeds $15 \mathrm{~mm} / \mathrm{sec}$. This is because the actual speed cannot catch up with the command speed due to a sudden change in the robot's

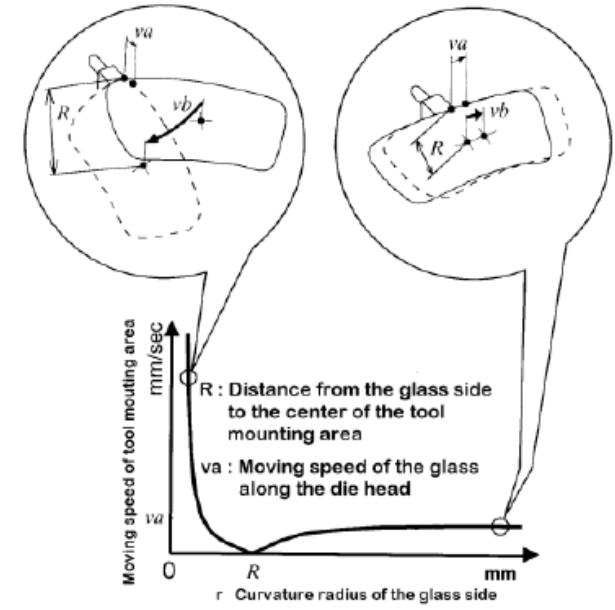

Figure 5: Relationship between glass curvature and robot movement velocity.

posture. Approximately five times the speed of robot movement is necessary to achieve the target.

Thus, the author has investigated the following items:

(a) Optimising the die head position, and

(b) Improving the robot control functions

\section{1.a. Optimizing the Die Head Position}

A vertical, articulated robot with six axes is employed in this study. The simulation of the movements at the various die head evaluated positions, shows that a limit occurs in the angular acceleration of the first axis and that the angular velocity of the fifth axis dominantly affects the angular acceleration of the first axis, as shown in Figure 6 (left). The ordinate of Figure 6 (right) shows the maximum angular acceleration of the first axis per step during the movement of the robot at each die head evaluation position. The abscissa shows the maximum angular velocity of the fifth axis per step. The die head position where the fastest moving speed of the tool mounting area can be obtained is designated as "Pj" where the load applied to the first axis, which has a large inertial mass, is the lowest. Since in this position the fifth axis can also provide high angular velocity, the author has chosen it as the die head position. As a result, the moving speed of the glass has been raised to approximately $40 \mathrm{~mm} / \mathrm{sec}$.

\section{1.b. Improving the Robot Control Functions}

One of the robot control functions is DFF (dynamic feed-forward). This function is used to variably control the servo motor gain following the robot's position and 

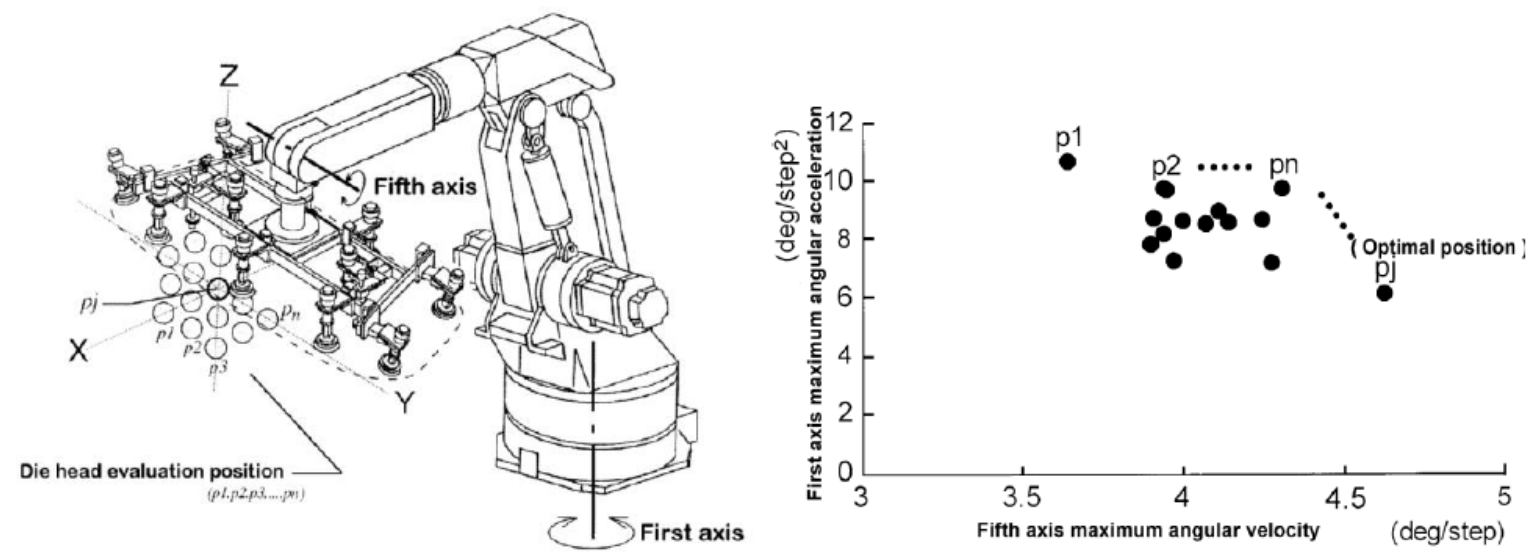

Figure 6: Simulation of robot movement. (left: die head evaluation position/right: optimizing the die head position).

posture so that a movement lag of the robot does not occur. In this study, to improve the tracking lag in the positions around the corners of the glass, the author has measured the inertia at the ever-changing robot posture during extrusion and then calculated the optimum gain for each teaching point. This analysis raised the speed up to $70 \mathrm{~mm} / \mathrm{sec}$. However, it is found that position correction is required at each teaching point due to the locus error that occurs along with the adoption of high-speed operation. The amount of correction increases proportionately to the moving speed. To solve this problem, the author has developed a method that could be applied to the extruding machine.

\subsection{Step 2: Variable Speed Extrusion}

Focusing on the fact that the robot has large possibilities in moving on the straight-line portion of the glass, the method is developed to reduce the extrusion time by increasing the traveling speed along the straight-line portion, as shown in Figure 7 (left). This is the method to obtain a mole with a constant crosssection by regulating the extrusion rate along with the acceleration and deceleration of the glass movement. This is called the variable speed extrusion.

In the conventional extruding process, it is necessary to keep a constant receiving speed to obtain a constant cross-section dimension of the mole. If the receiving speed is increased in the extruding process, the mole's cross-sectional area decreases because the extruding rate of plastics does not change. In this study, the fact that the variance in the robot's cycle movement is small, the author has established a cycle extruding control. Thus, the mole's cross-section shape as constant is successfully maintained by matching to the extruding pressure the moving speed of the glass, as shown in Figure 7 (right). As for the mass-

$\uparrow:$ Traveling speed of the glass
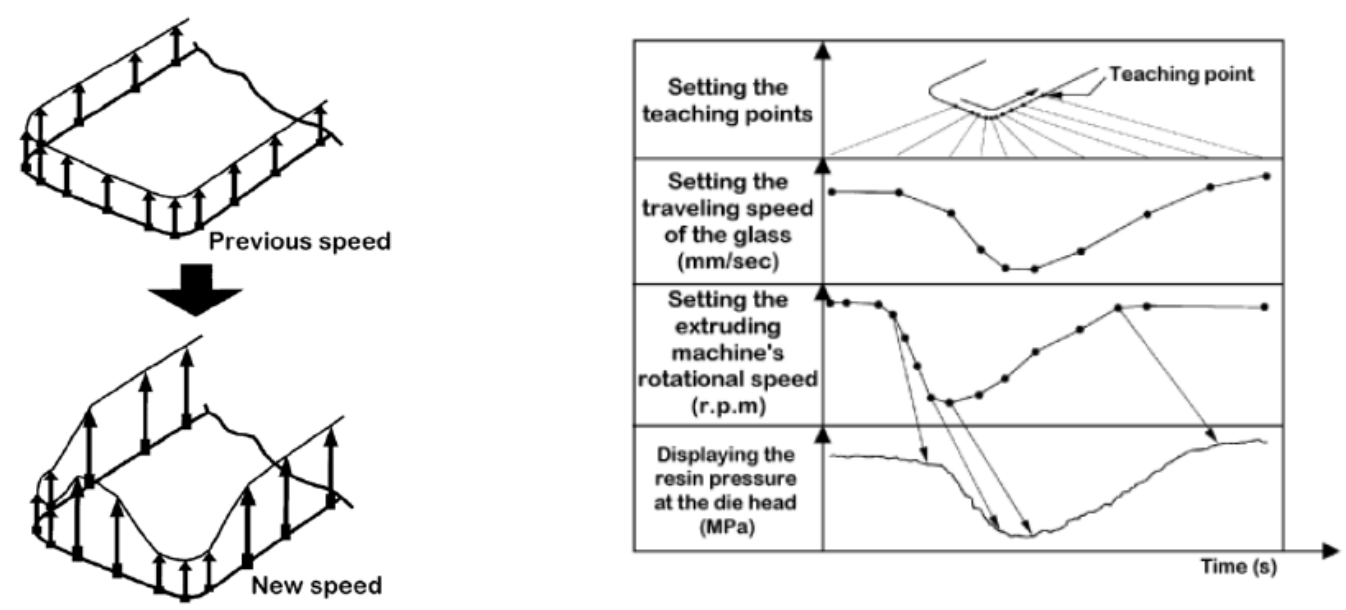

Figure 7: Variable speed extrusion. (left: traveling speed / right: conditions). 
production conditions, the speed of $100 \mathrm{~mm} / \mathrm{sec}$ was chosen along the straight-line portion and $40 \mathrm{~mm} / \mathrm{sec}$ around the corners, and thus reached the targeted time of $40 \mathrm{sec}$ per sheet.

\subsection{Step 3: Simultaneous Control of the Robot Movement and the Die Head Rotation}

Because the robot control and the extruding machine control must be individually adjusted through trial and error, the variable speed extruding process is very time-consuming.

In this paper, the author has incorporated a robot control method that is to rotate the die head by using the robot's seventh control axis and to control the moving speed of the glass around the corners synchronously, as shown in Figure 8 (left). This method gives $75 \%$ spare capacity, as compared with the previous method, to the robot's fifth axis, and thus raising the glass moving speed to $100 \mathrm{~mm} / \mathrm{sec}$ while keeping the extruding rate constant, as shown in Figure 8 (right). As a result, it has become possible to carry out production management and maintenance such as speed adjustment merely by controlling the robot.

\section{IMPROVING APPEARANCE QUALITY}

In the mole process, among the quality problems, "width change" and "drifting" of the mole shape are two important ones. In quality control of the mole, a target of $\pm 0.5 \mathrm{~mm}$ for width change in the cross-section and $\pm 0.3 \mathrm{~mm}$ (lip thickness of $\pm 0.1 \mathrm{~mm}$ ) for drifting is set. To reach the two targets, the following two items are studied as the technical issues that must be addressed:
Width change: Maintain the moving speed of the glass as constant

Drifting: Press the glass against the die head with uniform force

\subsection{Locus and Speed Control of the Extruding Point}

In the case of holding the glass and moving it against fixed points by using a robot, it is necessary to vary the control point data along the glass perimeter (on a real-time basis). In the past, it was only possible to playback the movements of the joints without interpolation movements. In that way, the teaching must be carried out at short intervals to obtain a smooth locus (Paul, 1981; Vukobratovic, 1982).

In this study, a model that uses an interpolation algorithm in controlling the glass moving is proposed. Suppose that the control point along the glass perimeter $(P c 1, P c 2, \ldots P c n, \ldots)$ are taught against a fixed operation point $P$, then at teaching point $\mathrm{Pc} 1$,

$\vec{P}=\overrightarrow{P_{T 1}} \cdot \overrightarrow{P_{T 1} P_{C 1}}$

$\therefore \overrightarrow{P_{T 1} P_{C 1}}={\overrightarrow{P_{T 1}}}^{-1} \cdot \vec{P}$

$\overrightarrow{P_{T 1}}=\tilde{M}_{11} \cdot \tilde{M}_{21} \cdot \tilde{M}_{31} \cdots \tilde{M}_{61}$

at the teaching point $\mathrm{Pc2}$,

$$
\begin{aligned}
& \vec{P}=\overrightarrow{P_{T 2}} \cdot \overrightarrow{P_{T 2} P_{C 2}} \\
& \therefore \overrightarrow{P_{T 2} P_{C 2}}={\overrightarrow{P_{T 2}}}^{-1} \cdot \vec{P}
\end{aligned}
$$
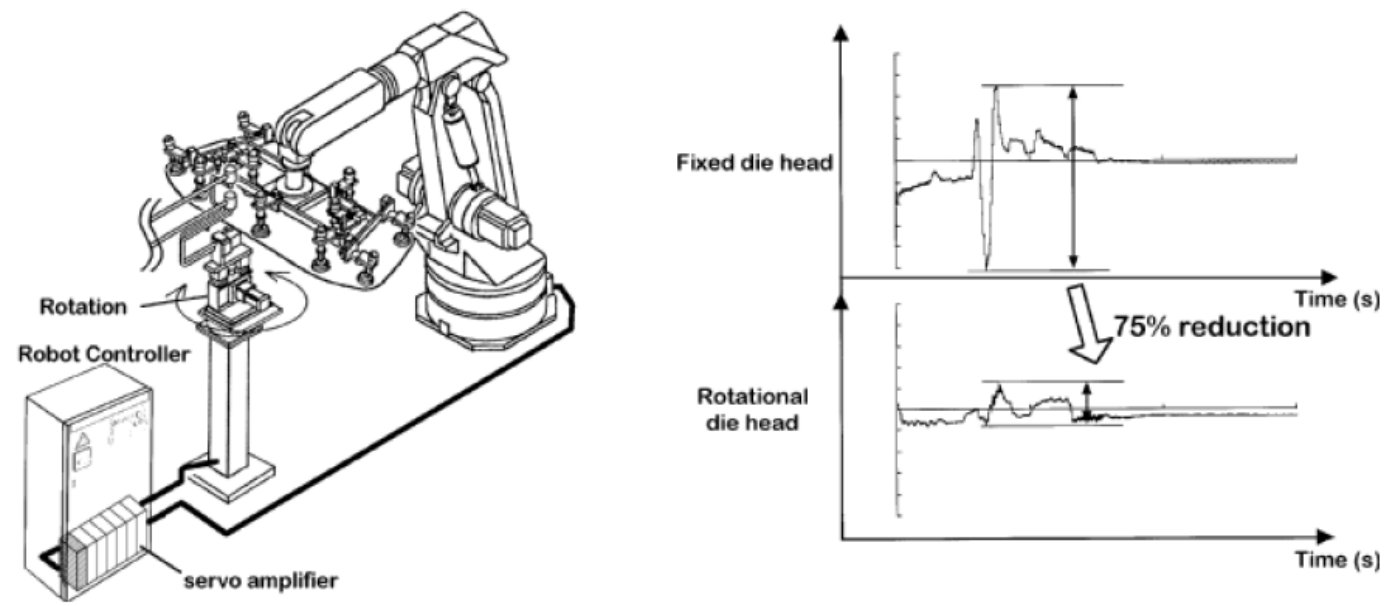

Figure 8: Synchronous control of die head rotation. (left: overview / right: comparison of robot load rates). 
During playback, the differential matrix $D(t)_{12}$

$$
D(t)_{12}=\left|\overrightarrow{P_{T 1} P_{C 1}}-\overrightarrow{P_{T 2} P_{C 2}}\right|
$$

is obtained.

The robot wrist flange center position $\mathrm{P}_{\mathrm{T}}(\mathrm{t})$ for each time interval between $\mathrm{P}_{\mathrm{C} 1} \sim \mathrm{P}_{\mathrm{c} 2}$ is obtained from

$$
P_{C}(t)=\overrightarrow{P_{T 1} P_{C 1}}+D(t)_{12}
$$

Thus,

$$
P_{T}(t)=\vec{P}^{-1} \cdot P_{C}(t)
$$

Finally, the amounts $\mathrm{J} 1 \sim 6(\mathrm{t})$ of the movement for each axis at time $t$ are obtained by solving the inverse matrix of $\mathrm{P}_{\mathrm{T}}(\mathrm{t})$.

Accordingly, the teaching process can be quite simplified. To solve this problem, furthermore, the feedforward element, which interpolates the speed drop, is introduced into the control to prevent the speed drop.

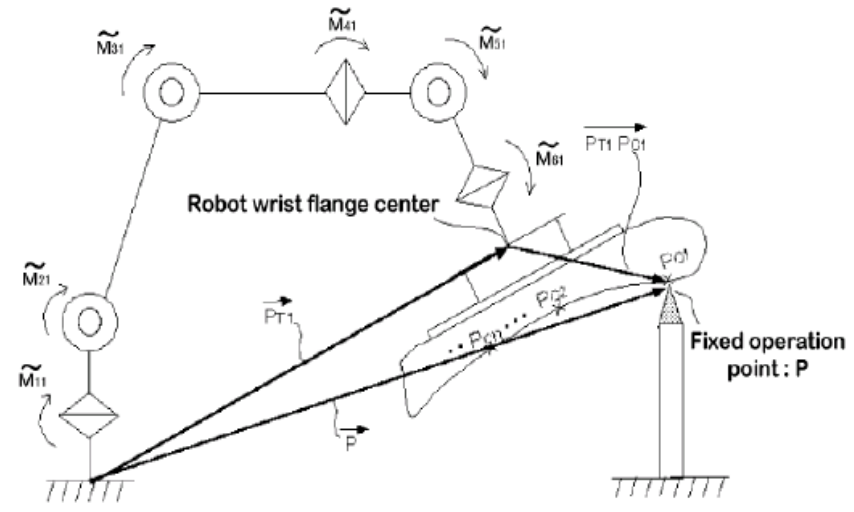

Figure 9: External reference point control (An, Atkeson, and Hollerback, 1981).

\subsection{Pressing Force Control}

The following methods for pressing the glass against the die head with a uniform force:

(a) Using a mechanical balance

(b) Using servo float function

As for (a), a seesaw device between the die head and a counterbalance is adopted as shown in Figure $\mathbf{1 0}$ (left). This method controls the force applied to the die head in the mole process at a constant level through a counterbalance (weight) by floating the die head up and down. Meanwhile, as for (b), a servomotor-driven elevating device is adopted as shown in Figure 11 (right). This is achieved by using the robot's eighth axis in the same way as that for rotating the die head. As the glass is placed in contact with the die head during the extrusion, the force applied to the die head drive motor (servo motor) is observed by the integrator described in the servo block diagram (hence the value of the force, which is the sum of the friction and the weight of the die head) and is stored in memory to make a gravity correction (Raibert, and Craig, 1981). While maintaining gravity correction, the gain is lowered to corresponding to external forces, which is applied to the die head in the up-down direction, thus giving a uniform pressing force. As a result, the die head is attached to the glass constantly. The optimum pressing force for extrusion is less than $30 \mathrm{MPa}$. From a series of experiments, it is found possible to control the pressing force below $17 \mathrm{MPa}$ for (a) and $125 \mathrm{MPa}$ for (b), respectively. By applying this method to the present system, the appearance quality is dramatically improved.
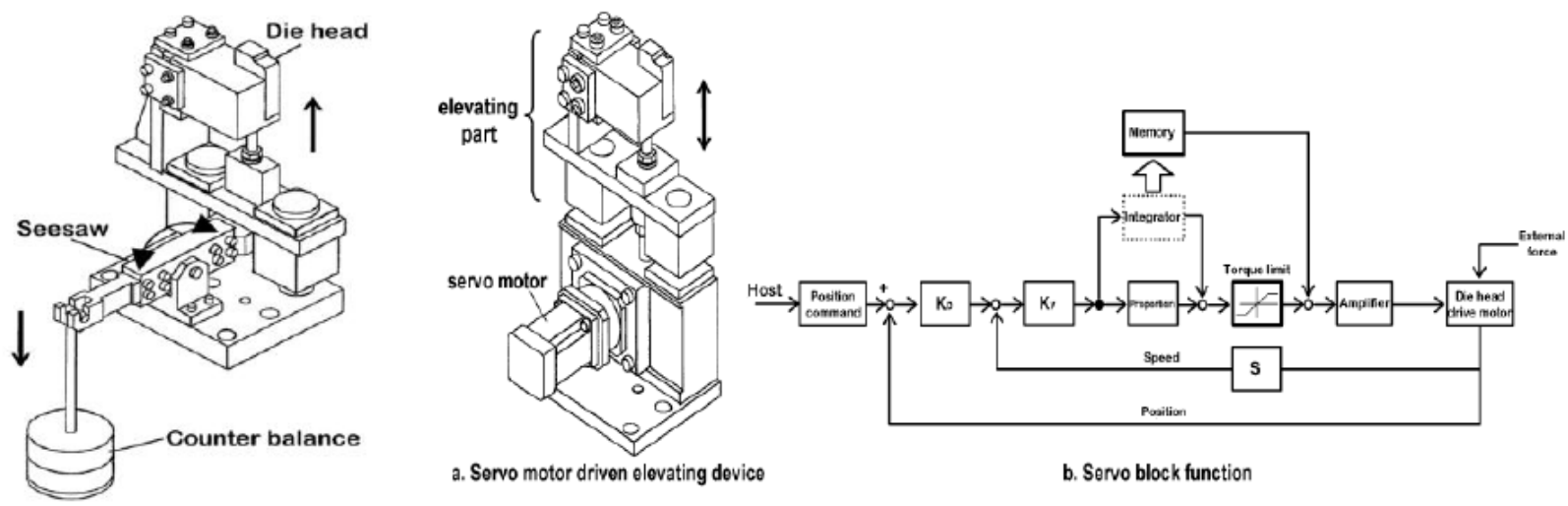

Figure 10: Methods for pressing the glass against the die head with a uniform force. (left: mechanical balance / right: servo float function). 


\section{APPLICATION}

A new manufacturing process has been developed that can extrude the mole directly onto the threedimensionally curved glass by using a combination of a robot and an extruding machine. By applying a robot to the processing of the plastic mole and making use of technologies such as real-time speed control, this system was realized. Because the moving speed of the glass drops around the corners, the author has optimized the movements of the robot, adopted a variable extruding rate, and developed synchronous control of the die head rotation.

These technologies enable the extrusion of the mole to be completed within the target time. To control the moving speed of the glass and the pressing force of the glass against the die head as constant values, the external reference point control and compliance control are introduced. Therefore, this system has successfully applied this system to the mass-production of vehicles at Toyota all over the world.

\section{CONCLUSION}

A highly reliable production system for global production was proposed for a smooth start-up of manufacturing technology to assure high quality, and the linkage to systematically manage processes in advance in individual stages of production planning, production preparation, mass production, and process control. Building the linkage has successfully eliminated the causes of overtime work and stopped declines in the availability of the assembly line in the process planning and line drawing stage.

It has also evaluated production operators' skills in advance for the concurrent engineering process to design the most suitable transportation based on that evaluation. There were two main purposes for creating a highly reliable production system. One of the purposes was to solve technical problems in advance by simulating with digital engineering. The other purpose was to share information globally by integrating data. For this purpose, the author has used IT including CG and DB as key technology and developed systems to visualize information (Sakai, and Amasaka, 2005). The results have been examined at Toyota Motor Corporation.

\section{REFERENCES}

[1] Amasaka K. Proposal and implementation of the Science SQC quality control principle, International Journal of Mathematical and Computer Modeling, 2004; 38(11-13): pp.
$1125-1136$

https://doi.org/10.1016/S0895-7177(03)90113-0

[2] Amasaka K. High linkage model Advanced TDS, TPS \& TMS: Strategic development of New JIT at Toyota, International Journal of Operations and Quantitative Management 2007; 13(3): pp. 101-121.

[3] Amasaka K, and Sakai $\mathrm{H}$. Improving the reliability of body assembly line equipment, International Journal of Reliability, Quality, and Safety Engineering 1996; 3(1): pp. 11-24. https://doi.org/10.1142/S021853939600003X

[4] Amasaka K, and Sakai $\mathrm{H}$. Availability and reliability information administration system ARIM-BL by methodology in inline-online SQC, International Journal of Reliability, Quality and Safety Engineering 1998; 5(1): pp. 55-63. https://doi.org/10.1142/S0218539398000078

[5] Amasaka K, and Sakai H. The new Japan global production model NJ-GPM: Strategic development of advanced TPS, Journal of Japanese Operations Management and Strategy, 2011; 2(1): pp. 1-15.

[6] An CH, Atkeson CG, and Hollerback JM. Model-based Control of a Robot Manipulator, The MIT Press, Cambridge, Massachusetts 1981.

[7] Chand G. and Shirvani B. Implementation of in cellular manufacture, Journal of Materials Processing Technology, 2000; 103(1): pp. 149-154. https://doi.org/10.1016/S0924-0136(00)00407-6

[8] Dhudshia VH. Hi-Tech Equipment Reliability: A Practical Guide for Engineers and the Engineering Manager, iUniverse, Inc., Bloomington 1996.

[9] Liker JK. The Toyota Way: Fourteen Management Principles from the World's Greatest Manufacturer, McGraw-Hill, New York 2004.

[10] Liker JK, and Hoseus M. Toyota Culture: The Heart and Soul of the Toyota Way, McGraw-Hill, New York 2008.

[11] Morgan J, and Liker JK. The Toyota Product Development System: Integrating People, Process and Technology, Productivity Press, New York 2006.

[12] Morikiyo Y. Review of distribution, communication and administrative sciences 1996; 22(1): pp. 1-24.

[13] Paul R. Robot Manipulators, Mathematics Programming and Control, The MIT Press, Cambridge, Massachusetts 1981.

[14] Raibert WH. and Craig JJ. Hybrid position / force control of manipulators, ASME Journal of Dynamic Systems, Measurement and Control 1981; 103(2): pp.126-133. https://doi.org/10.1115/1.3139652

[15] Sakai H. and Amasaka K. V-MICS, Advanced TPS for Strategic Production: Innovative Maintenance Combining DB and CG, Journal of Advanced Manufacturing Systems 2005; 4(1): pp. 5-20. https://doi.org/10.1142/S0219686705000540

[16] Sakai H. and Amasaka K. Strategic HI-POS, intelligence production operating system: Applying advanced TPS to Toyota's global production strategy, WSEAS Transactions on Advances in Engineering Education 2006; 3(3): pp. 223-230.

[17] Sakai, H. and Amasaka, K. Development of a robot control method for curved seal extrusion for high productivity for an advanced Toyota production system, International Journal of Computer Integrated Manufacturing 2007a; 20(5): pp. 486496.

https://doi.org/10.1080/09511920601160262

[18] Sakai H. and Amasaka K. Human intelligence diagnosis method utilizing advanced TPS, Journal of Advanced Manufacturing Systems 2007b; 6(1): pp. 77-95. https://doi.org/10.1142/S0219686707000905

[19] Sakai H. and Amasaka, K. Human digital pipeline method using total linkage through design to manufacturing, Journa of Advanced Manufacturing Systems 2007c; 6(2): pp. 101113.

https://doi.org/10.1142/S0219686707000929 
[20] Sakai H. and Amasaka, K. Human-integrated assist systems for intelligence operators, Encyclopedia of Networked and Virtual Organizations 2008; II(G-Pr): pp. 678-687. https://doi.org/10.4018/978-1-59904-885-7.ch089

[21] Taj S, and Berro L. Application of constrained management and lean manufacturing in developing best practices for productivity improvement in an auto-assembly plant, International Journal of Productivity and Performance Management 2006; 55(3/4): pp. 332-345.

https://doi.org/10.1108/17410400610653264

[22] Vukobratovic, P. Scientific Fundamentals of Robotics 1 and 2, Springler-Verlag, Berlin 1982.

DOI: https://doi.org/10.31875/2409-9694.2021.08.3

(c) 2021 Hirohisa Sakai; Licensee Zeal Press.

This is an open access article licensed under the terms of the Creative Commons Attribution Non-Commercial License (http://creativecommons.org/licenses/by-nc/3.0/), which permits unrestricted, non-commercial use, distribution and reproduction in any medium, provided the work is properly cited. 